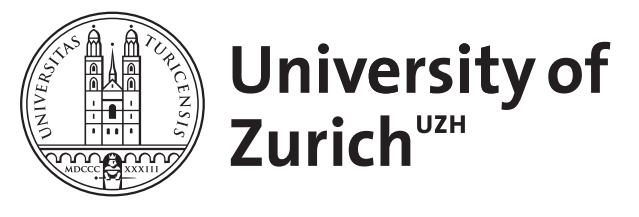

\title{
The Rise of NGO Activism
}

Daubanes, Julien ; Rochet, Jean-Charles

\begin{abstract}
Activist nongovernmental organizations (NGOs) increasingly oppose firms' practices. We suggest this might be related to the vulnerability of public regulation to corporate influence. We examine a potentially harmful industrial project subject to regulatory approval. Under industry influence, the regulator may approve the project even though it is harmful. However, an NGO may oppose it. We characterize the circumstances under which NGO opposition occurs and under which it is socially beneficial. Our theory explains the role that NGOs have assumed in the last decades, and has implications for the social legitimacy of activism and the appropriate degree of transparency of industrial activities.
\end{abstract}

DOI: https://doi.org/10.1257/pol.20180027

Posted at the Zurich Open Repository and Archive, University of Zurich ZORA URL: https://doi.org/10.5167/uzh-179642

Journal Article

Published Version

Originally published at:

Daubanes, Julien; Rochet, Jean-Charles (2019). The Rise of NGO Activism. American Economic Journal: Economic Policy, 11(4):183-212.

DOI: https://doi.org/10.1257/pol.20180027 


\title{
The Rise of NGO Activism ${ }^{\dagger}$
}

\author{
By Julien Daubanes and Jean-Charles Rochet*
}

\begin{abstract}
Activist nongovernmental organizations (NGOs) increasingly oppose firms' practices. We suggest this might be related to the vulnerability of public regulation to corporate influence. We examine a potentially harmful industrial project subject to regulatory approval. Under industry influence, the regulator may approve the project even though it is harmful. However, an NGO may oppose it. We characterize the circumstances under which NGO opposition occurs and under which it is socially beneficial. Our theory explains the role that $N G O$ s have assumed in the last decades, and has implications for the social legitimacy of activism and the appropriate degree of transparency of industrial activities. (JEL D21, D74, D82, L31, L51)
\end{abstract}

ctivist nongovernmental organizations (NGOs) increasingly influence industrial decisions. These NGOs are consumer associations, environmental groups, and stakeholders' advocacy groups that seek to prevent harmful projects and practices. ${ }^{1}$ They often convince firms to "self-regulate" when public regulation seems too lax. For example, companies such as Nike (early 1990s), Citigroup (2004), and HSBC (2012) significantly strengthened their social, environmental, and risk criteria after NGO intervention. Similarly, in 2013, Starbucks offered to pay taxes that it was not legally liable for, and, in 2015, Dunkin' Donuts stopped using potentially toxic nanoparticles allowed by the US Food and Drug Administration. Among

\footnotetext{
* Daubanes: GSEM at University of Geneva, Uni Mail, Boulevard du Pont-d'Arve 40, 1211 Geneva, Switzerland, and CESifo (email: julien.daubanes@unige.ch); Rochet: GSEM at University of Geneva, Uni Mail, Boulevard du Pont-d'Arve 40, 1211 Geneva, Switzerland, Swiss Finance Institute, and University of Zurich (email: jean-charles. rochet@bf.uzh.ch). Dan Silverman was coeditor for this article. We are grateful to two anonymous referees for suggestions that contributed to significantly improve the paper. We have also benefited from useful comments by participants at many seminars and conferences: Toulouse School of Economics; Indian Statistical InstituteDelhi Center; University of Ottawa; ETH Zurich; University of Oxford; CESifo Munich; Goethe University Frankfurt; University of Siegen; Paris West University; NGOs vs Regulators Zurich Conference; FAERE Toulon 2015; SCSE Montreal 2015; Frankfurt NGO Conference 2015; Montreal CIREQ Workshop; Aix-Marseille School of Economics; University of Geneva; University of St. Gallen; EAERE Zurich 2016; University of Copenhagen; Helsinki School of Economics; University of Maryland; Resources for the Future; OECD; and Paris GREENGO Workshop. Particular thanks to Saraly Andrade de Sá, Emmanuelle Auriol, David Baron, Marc Chesney, Vianney Dequiedt, Avinash Dixit, Guido Friebel, Christian Gollier, Jérôme Hergueux, Gerard Hertig, Chris Knittel, Jérémy Laurent-Lucchetti, Pierre Lasserre, Justin Leroux, Ross Levine, Tom Lyon, Thomas Mariotti, David Martimort, Michael Mehling, Rick van der Ploeg, Steve Salant, Aggey Semenov, Andrei Shleifer, Bernard Sinclair-Desgagné, Jason Shogren, Jean Tirole, Nicolas Treich, and Pierre-Yves Yanni for stimulating discussions and helpful suggestions. The research leading to these results has received funding from the European Research Council under the European Community's Seventh Framework Programme (FP7/2007-2013) grant agreement 249415-RMAC and the Swiss Finance Institute.

${ }^{\dagger}$ Go to https://doi.org/10.1257/pol.20180027 to visit the article page for additional materials and author disclosure statement(s) or to comment in the online discussion forum.

${ }^{1} \mathrm{~A}$ famous example of such opposition is the 1995 Greenpeace-Shell conflict over the dismantlement of the Brent Spar oil platform. Ironically in that case, the option ultimately chosen by the firm under NGO pressure turned out to be worse than the option initially approved by regulators.
} 
other contemporary issues, the release of endocrine disrupting chemicals (EDCs) by industry is center stage: although the inaction of public regulators-and the influence of the industry-is often denounced, under NGO pressure an increasing number of companies is committing to the goal of zero EDCs discharge-e.g., the Adidas Group.

By "NGO activism," we refer to the advocacy and militancy of civil society through not-for-profit organizations that are independent of public authorities and special interests. ${ }^{2,3}$ In general, NGO activists do not rely on the public order. They do "private politics," to use the words of Baron (2001): to oppose firms' projects and practices that they disapprove of, they use their private potential to harm these firms. This potential can be achieved in various ways-e.g., boycotts, naming and shaming, cyber activism, etc. ${ }^{4}$

NGOs' rising influence is one of the most significant changes in business over the past four decades (see Doh and Guay 2006, among others), ${ }^{5}$ with obvious implications for corporate management. Now more than ever, conflicts with NGOs do not only threaten firms' current business-for empirical evidence, see, for example, King and Soule (2007) and Harrison and Scorse (2010) — but are also costly in the long run in terms of reputation and brand value. Clearly, the risk of NGO opposition has become one of the most concerning threats for corporations, which management seeks to understand, anticipate, and address adequately. For a broad review on the strategic management of threats to business, see Gans and Kaplan's (2017) book; on the case of NGOs' reputation-destroying attacks, see also Culling (2017).

This paper puts forward an explanation for the rising influence of NGO activists. We model a firm that hopes to implement a project requiring the approval of a public regulator. The regulator may be influenced by the industry's interests, and thus may accept the firm's project even though it is socially harmful. An NGO may decide to oppose the project on the basis of its own information. NGO involvement impacts both the efficiency of public regulation and the economic performance of the industry. We characterize the conditions under which the NGO effectively opposes the project and the conditions under which this opposition improves social welfare. Our results, therefore, have not only implications for the occurrence of NGO activism, but also for its legal status.

Our view of NGO activism is reminiscent of Galbraith's (1952) notion of "countervailing power" that operates in the face of too-powerful industries: we depart from the outdated description of a society in which public regulation alone resolves market failures. More precisely, our theory holds that public regulation becomes vulnerable to industry lobbying as economic stakes grow, and that this induces NGO

\footnotetext{
${ }^{2}$ This definition excludes trade unions, which seek to generate gains for their members. It also excludes notfor-profit organizations whose funding is politically motivated—see, for example, Bertrand et al.'s (2018) recent empirical evidence of political influence through corporate philanthropy.

${ }^{3}$ We do not address other important facets of NGO activity; for example, on the provision of independent labelling services, see Heyes and Martin (2016) and the references therein.

${ }^{4}$ Activists' private nuisance potential sometimes also relies on the public order, as when activists file a lawsuit against a firm.

${ }^{5}$ For example, according to the Covalence Ethical Quote NGO database, 831 NGOs have leveled more than 18,000 criticisms against companies worldwide between 2002 and 2014. The data consist of negative reports published by NGOs against companies—see online Appendix A for a detailed description.
} 
activists to enter. In the presence of an NGO, public regulation may recover its resistance to the industry's interests. Otherwise, activists oppose industrial projects directly, and do so in a way that depends on both their mobilization efficiency and the transparency of the industry. NGO opposition is socially costly for two reasons. First, activists' mobilization consumes economic resources. Second, activists may mistakenly oppose socially beneficial projects due to both their bias and their imperfect information. However, when an NGO is sufficiently efficient and sufficiently well informed, it has the potential to improve social welfare. Our theory rests on a relationship between industry lobbying and NGO mobilization, for which we present some statistics in online Appendix A. Our theoretical predictions as to the entry of NGO activists and their welfare impact are used to explain and analyze the increasing involvement of NGOs in several industries over the past decades.

Baron $(2001,2003)$ was the first to propose a theory of private politics. He assumes that activists pursue social objectives. Their motivation may arise from moral preferences (Baron 2010), or from prosocial behavior à la Bénabou and Tirole (2006), and may depend on how well activists subscribe to the issue (Besley and Ghatak 2005). Baron (2010) shows how NGOs can emerge when socially concerned individuals coordinate their efforts in the spirit of Dixit (2004, ch. 3) and Tabellini (2008). When firms are targeted by activists, they may "self-regulate" to forestall this opposition and avoid the associated damages.

Recent papers that shed light on the relation between public regulation and private politics are complementary to our research. For example, Maxwell, Lyon, and Hackett (2000) studies how firms may self-regulate to avoid a strengthening of regulation inspired by activists. Following Baron (2003) and Baron and Diermeier (2007), we consider instead the alternative case in which NGOs oppose firms directly rather than by lobbying regulators. Indeed, over the period 2002-2014, for example, US-based NGOs' lobbying expenditures amounted to $\$ 2.3$ billion, while lobbying expenditures by US-based companies exceeded $\$ 36$ billion. ${ }^{6}$ One reason is that NGOs cannot match large firms' financial power. For example, Baron and Diermeier $(2007,600)$ reports the following statement by Greenpeace's former head, Paul Gilding, to the New York Times (June 2, 2001):

The smart activists are now saying, "O.K., you want to play marketslet's play." [Lobbying the government] takes forever and can easily be counter-lobbied by corporations... After all, consumers do have choices where they buy their gas, and there are differences now. Shell and BP Amoco ... both withdrew from the oil industry lobby that has been dismissing climate change.

Another reason for focusing on NGOs' direct confrontation with firms is that the internet and social networks have facilitated the dissemination of information and

\footnotetext{
${ }^{6}$ Source: Center for Responsive Politics. The above amounts are expressed in constant (2014) dollars; we have used the CPI-U consumer price index of the Bureau of Labor Statistics. To assess NGOs' lobbying expenditures, we have added the expenditures of all nonprofit organizations and the expenditures concerning various issues on which NGOs oppose the industry: human rights, the environment, foreign and defense policy, gun control, women's issues, and miscellaneous issues.
} 
lowered the cost of NGO opposition (Yu 2005). ${ }^{7}$ Lyon and Salant (2015) shows that NGO opposition is likely to reduce industries' subsequent influence on regulation. Finally, Egorov and Harstad (2017) studies the dynamics of the conflict between NGOs and firms, in a setup in which the intervention of a benevolent and independent regulator can put an end to such conflicts.

We contribute to the above literature in three ways. First and foremost, our theory explains, rather than assumes, the presence and intervention of NGO activists. More precisely, our theory allows for the opposition of activists after public regulators have approved a firm's project, as illustrated by our introductory examples. Our approach echoes Lyon and Maxwell's (2003) examination of public policy's alternatives in situations in which public regulation fails in the first place. In that sense, we contribute to answer the fundamental question why society relies on NGO opposition when externalities could have been resolved at the outset by public regulation. In our view, this is because the influence of firms on regulators is unavoidable, and can be counterbalanced by the direct intervention of NGO activists. Our contribution is complementary to the theory of Krautheim and Verdier (2016) who suggest that the proliferation of international NGOs has gone hand in hand with the process of globalization and firms' offshoring to low-regulation areas; their explanation relies on the geographical limitation of domestic public regulation, rather than the vulnerability of public regulators to the influence of the industry. Second, we highlight the key role of information asymmetries between NGOs and regulated firms. More precisely, we extend Baron's (2012) model of NGO opposition to the case in which activists' assessment of external costs depends on both the limited information at their disposal and their perception of the regulators' decisions. As Baron himself puts it $(2003,55)$, "the activist challenge to the firm begins with the identification of the issue." Large industrial projects are often opaque and/or complex, and, unlike regulators, NGOs have no legal mandate to examine them. For example, Greenpeace significantly overestimated the quantity of oil left in the Brent Spar platform in 1995 $(5,000$ tons instead of 50), because they had not collected enough samples during their illegal and perilous occupation of the platform. Third, our model takes into account that activists are essentially focused on external costs.

Whether NGO activism is optimal for society partly depends on the prevailing resistance of public regulation to the influence of the industry. In situations in which industrial interests have the potential to subvert public regulation, the economics of regulation has suggested that more regulation is needed to prevent harmful conduct, not only in developing countries (e.g., Stiglitz 1994), but also whenever regulatory capture is possible (Laffont and Tirole 1993, ch. 13). ${ }^{8}$ However, Glaeser and Shleifer (2003) shows that when law enforcement is weak, regulation may lead to corruption (see also Djankov et al. 2002). Similarly, when industry lobbying is intense, regulation enhances, rather than discourages, influence (e.g., Gibson Brandon and Padovani 2011). Our theory highlights NGOs' possible role in complementing

\footnotetext{
${ }^{7}$ On the role of public persuasion in NGO opposition, see, for example, Chiroleu-Assouline and Lyon (2016) and Couttenier et al. (2016).

${ }^{8}$ Laffont $(2005,57)$, however, suggests that regulation should be adjusted to the stage of development: situations of weak law enforcement may require less sophisticated regulatory schemes, and thereby provide weaker incentives.
} 
regulation. NGO opposition affects the performance of regulation in two basic ways. First, it renders public regulation less vulnerable to industrial interests, and second, it induces firms to self-regulate by abandoning their most hazardous projects. Yet the appeal of NGO intervention on top of public regulation relies on NGOs' efficiency, in both identifying and opposing the most hazardous projects.

The rest of the paper is organized as follows. Section I presents a basic model in which public regulation can be influenced by the industry it supervises. Section II introduces NGO opposition. Section III examines the impact of NGO opposition on public regulation. Section IV assesses the vulnerability of public regulation with and without NGO opposition, and examines the circumstances under which NGO opposition arises and contributes to social welfare. Section V draws implications for the recent rise of NGOs, as well as policy implications about transparency and about the legal status of NGO activism. Section VI concludes.

Online Appendix A provides suggestive statistics about the relationship between industry lobbying and NGO mobilization in the United States. Online Appendix B gathers the proofs of the propositions that are not in the main text. Online Appendix $\mathrm{C}$ presents our view of corporate influence, the failure of regulators, and NGO activism in more details. Online Appendix D shows how our analysis accommodates more complex environments.

\section{A Model of Public Regulation with Industry Influence}

The recent performance of public regulators is mixed. For example, catastrophes such as the explosion of the Deepwater Horizon oil-drilling rig in 2010 and the Fukushima Daiichi disaster in 2011 suggest that regulators have sometimes failed to impose adequate standards on the industries they were supposed to monitor. Furthermore, these examples indicate a reason for this failure: industries can influence their regulators. Goldberg and Maggi (1999) shows that industries do influence public policies and regulations in their favor. This influence has mostly been documented for the banking sector in the empirical literature that emerged following the global financial crisis of 2007-2009.

In fact, there are two different views of the corporate lobbying process, with opposite implications about its social usefulness. On the one hand, a large part of the theoretical literature assumes that lobbyists are experts who produce and transmit information to uninformed policymakers - see, among others, the influential models of Dewatripont and Tirole (1999) and Grossman and Helpman (2001). On the other hand, many believe that lobbyists seek to influence rather than inform. Indeed, anecdotal evidence suggests, and Bertrand, Bombardini, and Trebbi's (2014) empirical study confirms, that the success of a lobbyist is more a matter of connections than expertise. Moreover, our paper does not deal with legislators but with regulators, who are appointed for their expertise. For these two reasons, our model adopts the second view on lobbying, namely that it is about influence rather than information.

Precisely, we introduce influential industry lobbying into an otherwise standard model of public regulation. A single firm, representative of the industry, can undertake some project. For example, the firm may implement a new operational unit or financial technique, release a new consumer product, etc. The project has a fixed 
(exogenous) size $q>0$. It generates both a net private value $v q>0$ that accrues to the industry and a net external cost $c q$ that is borne by the rest of society (e.g., consumers or workers).${ }^{9}$ The external cost reflects the fact that a new operational unit, a new product or a new technique may turn hazardous for the environment, for consumers, or for financial stability.

There are two possibilities: either the project is good or it is bad, depending on whether the private value $v q$ covers or falls short of the external cost $c q$. Precisely,

$\left\{\begin{array}{l}\text { with probability } p_{L} \text {, the project is good, as its external cost is low: } c=c_{L}<v \\ \text { with probability } p_{H} \text {, the project is bad, as its external cost is high: } c=c_{H}>v\end{array}\right.$

The firm would always undertake the project, since it generates a profit $v q>0$. However, the project may be bad for society (when $c=c_{H}$ ). An expertthe regulator-is delegated the decision to approve or reject the project, ${ }^{10}$ as in the two-tiered regulatory structures of Tirole (1986), Laffont and Tirole (1991), and Laffont (1994). This literature focuses on the asymmetry of information between the firm and the regulator regarding private production costs. By contrast, we focus on the external effects of the firm's projects-e.g., on the environment, consumers' health, or the financial system - which are monitored by specialized regulatory agencies. In this context, we make the simplest assumption that the information available to the firm and the regulator is symmetric and perfect: both the firm and the regulator perfectly observe whether the project is good $\left(c=c_{L}\right)$ or bad $\left(c=c_{H}\right)$. In particular, this means that there is no moral hazard; for an analysis of more complex situations in which firms' hidden actions can influence the external costs of their projects, see Hiriart, Martimort, and Pouyet (2010).

The original feature of our model is lobbying: the industry can ex ante (i.e., before the external cost is observed) influence the preferences of the regulator by making lobbying expenditures $e \geq 0$. In the spirit of Hiriart and Martimort (2012), we assume that lobbying causes the regulator to be biased in favor of the industry. Denoting by $\pi=v q$ and $\mathcal{C}=c q$, respectively, the firm's profit and the external cost borne by the rest of society when the project is undertaken, the total surplus generated by the project is $\pi-\mathcal{C}$. Under the industry's influence, however, the regulator pursues the biased objective ${ }^{11}$

$$
\mathcal{V}=(1+\alpha(e)) \pi-\mathcal{C}=[(1+\alpha(e)) v-c] q,
$$

\footnotetext{
${ }^{9}$ The net private value is the difference between the private revenue and the private cost of the industry. The net external cost is the difference between the social cost (due to health or environmental damages, for example) and the benefit of stakeholders (e.g., consumers or workers) who bear this social cost.

${ }^{10}$ Our simple model assumes that a rejected project is not undertaken. Were a project modified after a rejection, it would be considered as a new one.

${ }^{11}$ The regulator's objective need not integrate the ex ante lobbying expenditures of the industry, which are sunk at the moment of the regulatory decision to accept or reject the project. Those expenditures will, however, be considered later in our analysis of social welfare.
} 
where the regulatory bias $\alpha(e) \geq 0$ positively depends on the firm's lobbying expenditures $e \geq 0$. We assume a linear influence function

$$
\alpha(e)=\frac{e}{i},
$$

where the parameter $i>0$ should be interpreted as the marginal cost of influence. When $e=0$, there is no lobbying, and the regulator is not influenced at all: $\alpha(0)=0$. In that case, the objective (1) coincides with the surplus $\pi-\mathcal{C}$ generated by the project and the regulator allows the project when it is good and rejects it otherwise.

Lobbying takes place when $e>0$, which leads the regulator to give the extra weight $\alpha(e)>0$ to the industry's profit relative to the external cost. Sufficient lobbying expenditures can induce the regulator to approve the project not only when it is good, but also when it is bad. In the absence of an NGO, we obtain the following proposition, whose proof is presented in online Appendix B.

PROPOSITION 1 (Regulation and lobbying with no NGO): In the absence of an $N G O$,

(i) The regulator approves a bad project if and only if

$$
\alpha(e) \geq \bar{\alpha} \equiv \frac{c_{H}-v}{v} ;
$$

(ii) Lobbying takes place if and only if

$$
\frac{i}{q} \leq\left(\frac{i}{q}\right)^{R} \equiv \frac{p_{H} v^{2}}{c_{H}-v}
$$

Note that if lobbying were assumed ex post-i.e., specific to the project's typeinstead of ex ante, our results would remain qualitatively the same: in that case, lobbying would take place only when the project is bad and if $i / q \leq v^{2} /\left(c_{H}-v\right)$.

The threshold $\bar{\alpha}>0$ defined in (3) measures the minimum influence that the industry must have to convince the regulator to allow all projects. According to (4), the occurrence of lobbying depends on the parameter $i / q$, which measures the relative cost of influence, which is adjusted by the size of the project.

In the absence of lobbying, the social surplus generated by the industry is positive because the project is only allowed if it is good $\left(c=c_{L}\right)$. We denote this first-best surplus by

$$
\mathcal{W}_{L}^{R}=p_{L}\left(v-c_{L}\right) q>0 .
$$

With industry lobbying, however, it may not be so. Expected welfare in that case can be written as

$$
\mathcal{W}_{L H}^{R}=p_{L}\left(v-c_{L}\right) q+p_{H}\left(v-c_{H}\right) q-i \bar{\alpha},
$$


which differs from $\mathcal{W}_{L}^{R}$ in (5) by its second and third terms, which are both negative. The second term reflects the fact that the project is approved and undertaken even when it is bad. The third term further reduces social welfare by the industry's resources that have been sunk into lobbying. We assume, nevertheless, that the expected social welfare generated by the industry is nonnegative, despite the industry's influence:

$$
\mathcal{W}_{L H}^{R} \geq 0
$$

This rules out the uninteresting situation in which it would be socially optimal to simply prohibit all projects ex ante.

\section{NGO Activism}

Public regulators have certainly experienced a golden age. Glaeser and Shleifer (2003) explains the predominance of public regulation at the end of the nineteenth and the beginning of the twentieth centuries by the fact that it proved more resistant than other social control mechanisms in the face of growing industrial interests. Since then, however, regulators have, to a large extent, lost public trust, as argued by Aghion et al. (2010). Trust barometers further reveal that the public believes that industries are inadequately regulated, and trusts NGOs significantly more than public authorities. Accordingly, we suggest that the recent rise of NGO activism is a response to the failure of public regulation. Indeed, over the period 2002-2014 in the United States, for example, NGOs' criticisms against companies have been positively associated with prior increases in companies' lobbying expenditures (see the details in online Appendix A).

We introduce in the model of Section I an activist NGO that may decide to interfere in the regulatory process. We focus on confrontational activists that do not lobby regulators, but mobilize directly against the firm's project, as in our introductory examples (e.g., Baron 2003, 2012).

Nature first determines whether the project is good or bad, which is observed by the regulator. In either case, the regulator decides whether to reject or approve it. If the project is not approved, nothing else happens-but if it is approved, activists enter the discourse. ${ }^{12}$

\section{A. NGO-Industry Confrontation}

When the project is approved by the regulator, the activists evaluate its external cost and decide whether to oppose it - the information available to activists and their assessment of the external cost will be detailed further below. As far as the

\footnotetext{
${ }^{12}$ The timing of actions, therefore, assumes that NGO opposition takes place after the regulatory decision whether to reject or approve the project. In some cases, however, NGOs identified potentially hazardous industrial projects that were still on the track for approval-i.e., before they were approved. Public regulation was sometimes sensitive to NGO opposition in these situations - as, for example, when fracking was banned by various US states and European governments. For an analysis of situations in which activists oppose firms' projects first, until public regulation puts an end to the conflict, see Egorov and Harstad (2017).
} 
activists' opposition is concerned, we rely on Baron's (2012) model of confrontational activism. ${ }^{13}$ Their opposition consists of two stages: activists first mobilize, then campaign if needed. No successful campaign can arise without prior mobilization efforts. For example, in the 2004 conflict in which Rainforest Action Network opposed Citigroup's financing of environmentally harmful projects, the NGO first committed personnel and earmarked funds to the issue, and engaged in specific public communication, before demanding that the bank strengthen its environmental standards. ${ }^{14}$ In the first stage, the activists mobilize with an intensity

$$
m \geq 0
$$

against the project. We assume that mobilization efforts $m$ are publicly observable and entail a dead weight loss $\gamma m$, where $\gamma>0$ is the marginal cost of mobilizing. When $m=0$, we say that the activists do not mobilize. In that case, the approved project is ultimately undertaken by the firm.

Facing mobilization, the industry can always self-regulate. Given an intensity of mobilization $m>0$, the firm decides whether to abandon or continue the project. If the firm abandons the project, nothing else happens.

When the project is opposed but continued by the firm despite the mobilization, the activists launch a campaign against it with the intent to hurt the firm. For example, in its conflict against Citigroup, Rainforest Action Network urged Citigroup cardholders to cut their cards into pieces and mail them to the bank. In the conflict between As You Sow and Dunkin' Donuts, the former ultimately coordinated a hostile shareholder resolution. These actions can take the form of calling for a boycott, mounting a cyber attack, launching a negative advertisement campaign, lawsuit, shareholder resolution, etc. ${ }^{15}$ This is the second stage of the activists' opposition. In addition to the NGO's mobilization efforts, a large variety of factors that are not under the NGO's control determine the success of a campaign. Therefore, a campaign randomly generates a harm $h \geq 0$ to the firm. We assume that $h$ is drawn from a uniform distribution of support $[0, m]$ :

$$
h \sim U[0, m] .
$$

Given the realized harm $h$, the firm decides whether to concede to the campaign. If the firm does not concede and undertakes the project despite the campaign, it bears the harm $h$ that reduces its profit accordingly. If the firm concedes to the campaign, it is only inflicted a fraction

$$
\omega \in(0,1)
$$

\footnotetext{
${ }^{13}$ This model was inspired by the well-documented conflict in which the NGO Rainforest Action Network opposed Citigroup in 2004 (Baron and Yurday 2004).

${ }^{14}$ In general, NGO mobilization involves public communication. This is reflected, for example, by the criticisms leveled by NGOs against companies, which are described in online Appendix A.

${ }^{15}$ Various modes of campaigning, including boycotts, lawsuits, and shareholder resolutions, may sometimes be directed to the news media and amount to harmful advertising. See, for example, Friedman $(1999,181-95)$ on the effects of boycotts.
} 


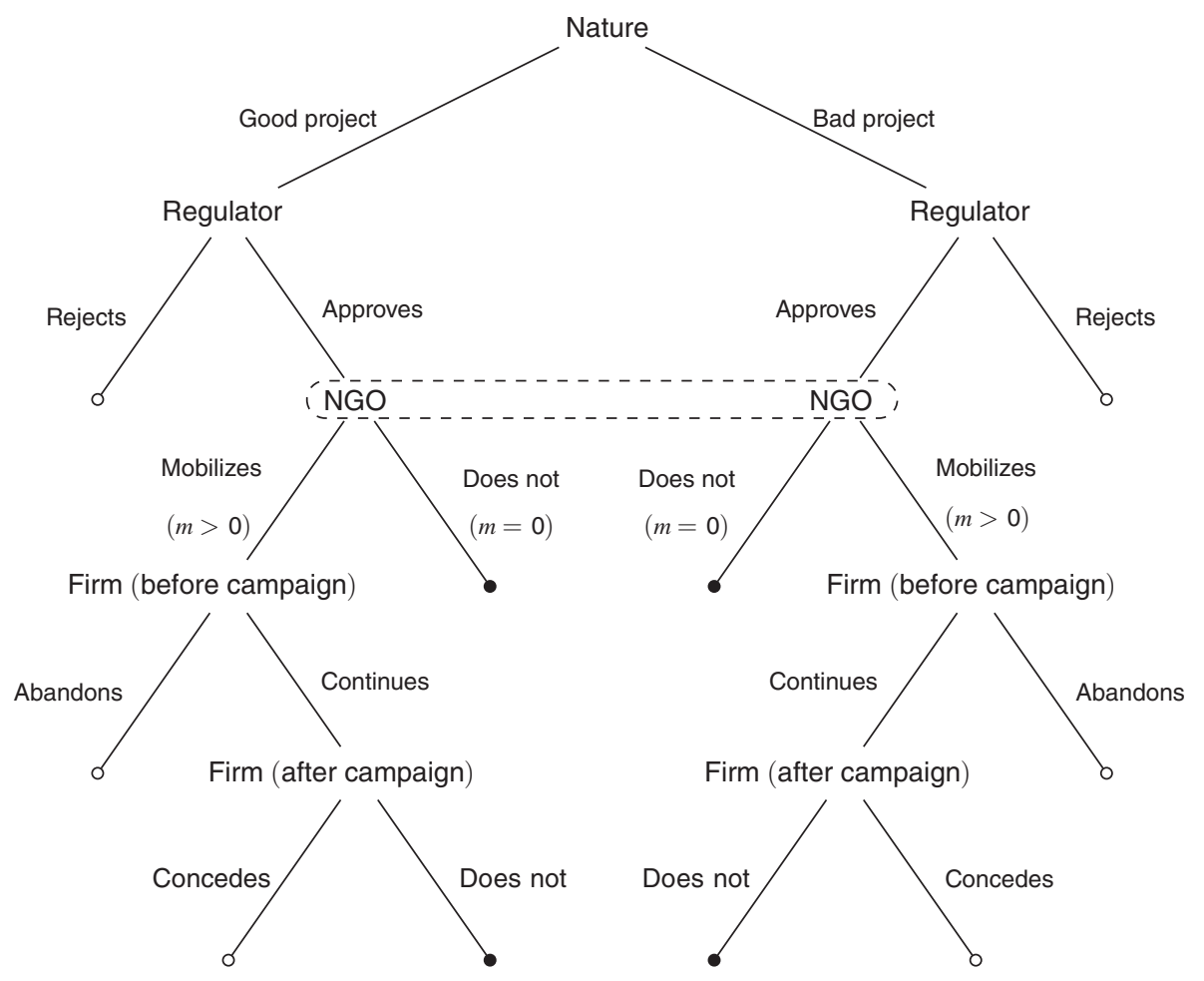

Figure 1. GAME Form

of the harm $h$. That is, conflict always negatively impacts the firm, but less so when it ultimately concedes. In that case, the harm $\omega h$ reflects the persistency of campaign damages, such as when society does not immediately forgive the firm after its concession, which causes a loss in terms of reputation or brand value.

The timing of actions is summarized by the game form presented in Figure 1. The regulator acts first (after Nature has determined the project's type), then the NGO, and finally the firm. The information set encompassing the NGO nodes represents the fact that the NGO does not observe whether the project is good or not, but only receives a signal about the external cost-see further below. Solid nodes indicate that the project is ultimately undertaken. Hollow nodes indicate that it is not, either because it has been rejected by the regulator, or because it has been abandoned by the firm. The firm may abandon the project after NGO mobilization, i.e., before a campaign — or, if it continues with the project, after the campaign or not at all. The game is solved backward, so as to select a subgame perfect equilibrium. We start with the firm's decision.

\section{B. The Firm's Reaction to Activism}

Our results are summarized by the following lemma-its proof is presented in online Appendix B. 


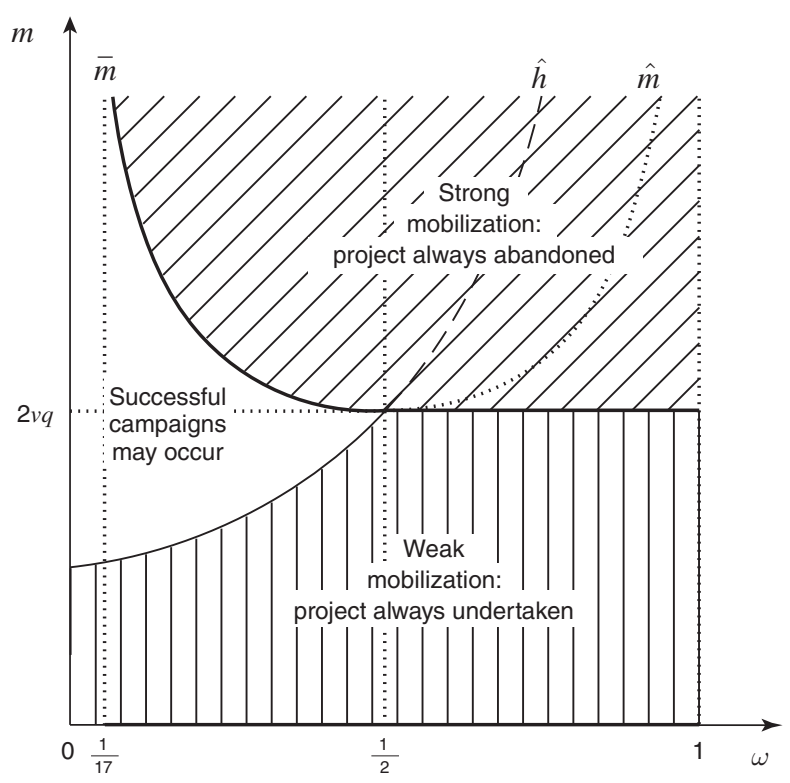

Figure 2. ImpaCt of NGO Mobilization and the NGO's Optimal Strategies

LEMMA 1 (Firm's reaction to activism): The firm will abandon the project

(i) Either after a campaign if it is sufficiently harmful:

$$
h \geq \hat{h} \equiv \frac{v q}{1-\omega} ;
$$

(ii) Or immediately after a mobilization if it is sufficiently intense:

(10) $m \geq \bar{m} \equiv \eta(\omega) v q, \quad$ with $\eta(\omega)=\left\{\begin{array}{ll}\frac{1}{\sqrt{\omega(1-\omega)}} & \text { if } 0<\omega<\frac{1}{2} \\ 2 & \text { if } \frac{1}{2} \leq \omega<1\end{array}\right.$.

In the $(\omega, m)$ plane, Figure 2 represents the increasing curve $m=\hat{h}$ expressed in (9), the decreasing curve $m=\bar{m}$ expressed in (10), as well as the U-shaped curve $m=\hat{m}$ defined and used in the Proof of Lemma 1 (online Appendix B). The intersection of these curves at $\omega=1 / 2$ implies two main cases of analysis. When a mobilization induces the firm to abandon the project immediately, we call it "strong." When it does not, and no campaign causes the firm to concede, the mobilization is called "weak."

The Case of Highly Persistent Campaign Damages: $\omega \geq 1 / 2$.-As Figure 2 shows, $\omega \geq 1 / 2$ implies $\bar{m} \leq \hat{h}$. In that case, the mobilization is strong-inducing the firm to abandon the project immediately - if and only if $m \geq \bar{m}$. Otherwise, the firm continues and the subsequent campaign necessarily satisfies $h<\hat{h}$, because $h \leq m<\bar{m} \leq \hat{h}$. Therefore, a mobilization that is not strong-inducing the firm 
to continue - is, therefore, necessarily weak — not causing the firm to concede after a campaign. As will be clear shortly below, the activists are sensitive to the cost of mobilization; it cannot be optimal for the NGO to make unnecessarily costly mobilization efforts. As a result, the NGO makes either the cost-effective strong mobilization of intensity $m=\bar{m}$-this is sufficient to induce the firm to abandon the project—or does not mobilize at all. Note that, when $\omega \geq 1 / 2$, no NGO campaign takes place in equilibrium. For the sake of completeness, we now examine the case of low persistent damages $(\omega<1 / 2)$, which is more complex.

The Case of Low Persistence of Damages: $\omega<1 / 2$.-By contrast, potentially successful NGO campaigns may take place when $\omega<1 / 2$. Indeed, Figure 2 shows that, in that case, there exist mobilizations that are neither weak, nor strong: mobilization intensities $m \in(\hat{h}, \bar{m})$ do not induce the firm to self-regulate immediately after the mobilization, but are able to generate successful campaigns to which the firm would concede. Therefore, there are three possible cost-effective options for the NGO, rather than two. The first option is not to mobilize at all $(m=0)$. The second option is to make the strong mobilization efforts $m=\bar{m}$ that induce the firm to abandon the project immediately. The third option is to make intermediate mobilization efforts $m \in(\hat{h}, \bar{m})$, knowing that the firm will not immediately self-regulate, but hoping that the subsequent campaign will be sufficiently successful to make it ultimately concede.

\section{The NGO Choice of Mobilization Intensity}

We depart from Baron's (2012) assumption that the activists maximize social welfare. Instead, we assume that they are solely concerned with the external cost $\mathcal{C}$ generated by the project. Indeed, as a matter of fact, activist NGOs are typically specialized in social, environmental, or risk-related issues, which they consider as priority. More precisely, the NGO chooses its mobilization intensity $m$ in such a way as to minimize

$$
\chi=E^{N}[\mathcal{C}]+\gamma m
$$

where the superscript $N$ means that the expectation is conditional on the information available to the $\mathrm{NGO}$ - see below for details.

We focus on the case where $\omega$ is not too low-i.e., campaign damages are sufficiently persistent - to reflect the fact that reputational risk has become a major concern for companies. As The Economist (January 22, 2004, Special Report on Risk) puts it, "The biggest risk any company faces is the loss of its good name, and you cannot insure against that." Interestingly, the special report adds that "some of the most vigorous wreckers of reputations have been NGOs." Even in the eventuality of a concession, therefore, a conflict with activists may be prohibitively costly in terms of both reputation and brand value. ${ }^{16}$

\footnotetext{
${ }^{16}$ The Economist's special report continues: "Greenpeace and Friends of the Earth now routinely picket and boycott firms of whose practices they disapprove, such as Nestlé, Esso, and Shell. Companies that do business in poor countries (e.g., Nike) are liable to find themselves charged with running sweatshops."
} 
When $\omega$ is not too low, online Appendix B establishes that the persistency of campaign damages is such an important concern for the firm that the NGO does not find it optimal to make intermediate mobilization efforts $m \in(\hat{h}, \bar{m})$, which do not induce the firm to immediately self-regulate. Indeed, in that context, if the firm decides to continue after the mobilization, the subsequent campaign is too unlikely to be successful. In this regard, online Appendix B identifies the threshold $\omega=1 / 17$ as critical. Therefore, we make the following assumption, which not only simplifies the analysis, but also eliminates situations of least relevance.

ASSUMPTION 1 (Campaign Damages Persistency): Campaign damages are suffciently persistent:

$$
\omega \geq \frac{1}{17}
$$

The following proposition is obtained.

PROPOSITION 2 (NGO Mobilization Intensity): Under Assumption 1, no activists' campaign occurs in equilibrium.

(i) Either the NGO does not mobilize $(m=0)$, and the project is undertaken by the firm;

(ii) Or it mobilizes with the lowest intensity $m=\bar{m}$ that induces the firm to immediately abandon the project.

In Figure 2, these two mobilization intensities that may be optimal for the NGO appear in thick curves.

The proof is presented in online Appendix B. Assumption 1 implies that activist campaigns never occur in equilibrium; the resulting game form is represented in Figure 3. Therefore, it allows our analysis of the NGO-industry confrontation to focus on the industry's self-regulation in the face of activists' mobilization, highlighting the empirically most important facet of NGO activism. Admittedly, mobilizations do not always suffice, such that firms sometimes concede to activists' requests after harmful campaigns have been carried out. ${ }^{17}$ In our framework of analysis, campaigns might take place if the persistency of campaign damages were very low: $0<\omega<1 / 17$ - online Appendix B establishes the exact conditions under which they effectively occur. As a matter of fact, nevertheless, those campaigns are only the tip of the iceberg; in many more cases, although perhaps less noticeable, firms proactively self-regulate as they are confronted with a latent mobilization of NGO activists, in order to avoid the possibility of harmful campaigns (Baron 2003, 36). Innes and Sam (2008), for example, finds empirical evidence that firms tend to

\footnotetext{
${ }^{17}$ As already mentioned, this was the case, for instance, in the 2004 conflict between Rainforest Action Network and Citigroup, in the 2012-2013 conflict between UK Uncut and Starbucks, and in the 2015 conflict between As You Sow and Dunkin' Donuts. In fact, the most famous examples of NGO activism involve a campaign-for example, a boycott—because such conflicts are the most noticeable manifestation of NGO opposition.
} 


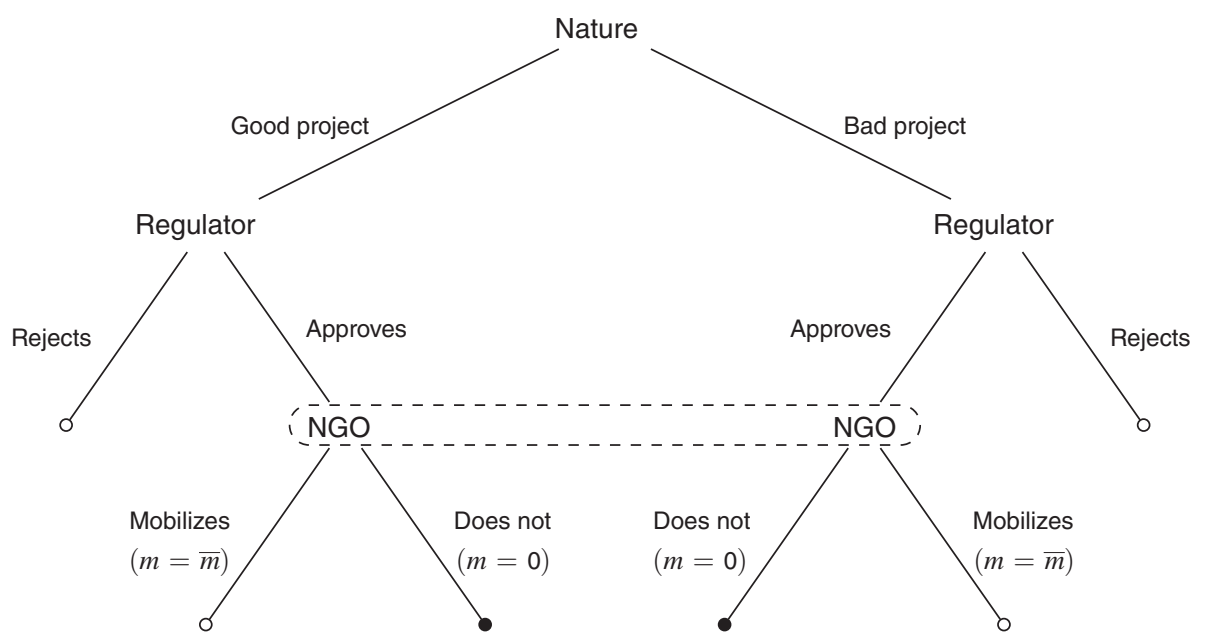

Figure 3. Reduced-Game Form AFter Two Steps of Backward INDUCTION

self-regulate more when they are more likely objects of a consumer or environmental group boycott. Culling $(2017,58)$ defends the view that corporations are highly sensitive to reputation-destroying attacks by activists and examines how managers can, and why they should, avoid long-term reputational damage: in the event of a crisis, as he puts it, "corrective action is the only option" and "should be viewed in the context of avoiding an extension or exacerbation of the crisis."

We now characterize activists' optimal choice to mobilize or not against the firm's project.

\section{The NGO Information and Decision}

According to Proposition 2, the NGO's optimal strategy is either not to mobilize $(m=0)$, in which case the project is undertaken, or to mobilize with the minimum effective intensity $\bar{m}=\eta(\omega) v q$ needed to induce the project's abandonment. In the first case, $\chi=E^{N}(c) q$, where $E^{N}(c)$ denotes the NGO's assessment of the external cost $c$, while $\chi=\gamma \eta(\omega) v q$ in the second. It follows that the NGO opposes the project if and only if

$$
E^{N}(c) \geq \bar{s} \equiv \gamma \eta(\omega) v .
$$

Otherwise, there is no mobilization and the project is undertaken.

Complete Information.-Suppose first, as in Baron's (2012) original model, that the NGO is perfectly informed about the project's external cost $c$. It follows that the NGO opposes the project if and only if its external cost $c=c_{L}, c_{H}$ exceeds the threshold $\bar{s}$ expressed in (13). There are three possibilities: (i) if $\bar{s} \leq c_{L}$, the NGO always opposes the project, irrespective of whether it has a high $\operatorname{cost} c_{H}$ or a low cost $c_{L}<c_{H}$. (ii) If $c_{H}<\bar{s}$, on the contrary, the NGO always remains inactive: it never 
opposes the project, even when it perfectly knows that it is bad. (iii) Otherwise, $c_{L}<\bar{s} \leq c_{H}$, and the perfectly-informed NGO only induces the abandonment of the project when it is bad, as in the first-best outcome. In either of cases (i) and (ii), the NGO is "extremist" in the sense that its decision is independent of the (perfect) information at its disposal, making the analysis less interesting.

No Information.- -Suppose now that the NGO has no information at all on the project's external cost. Whether the project is good or bad, the activists' assessment of its cost is simply the prior $E^{N}(c)=p_{L} c_{L}+p_{H} c_{H}$. There are two possibilities. Either $\bar{s} \leq p_{L} c_{L}+p_{H} c_{H}$, in which case the NGO is also extremist: it systematically opposes the project despite the fact that it has no information at all about its cost. Or $p_{L} c_{L}+p_{H} c_{H}<\bar{s}$, in which case the NGO remains inactive when it is uninformed.

Incomplete Information.-Here, the assessment of the external cost $c$ by the activists depends on both their perception of the regulator's behavior and the (imperfect) information at their disposal. We represent the latter as the following noisy signal on $c$ :

$$
s=c+\sigma \varepsilon,
$$

where $\varepsilon$ is the realization of a random noise with zero mean, density $f(\varepsilon)$, and cumulative distribution function $F(\varepsilon)$. We assume that $f$ is symmetric and single peaked at $\varepsilon=0$. We also assume that $\log (f)$ is strictly concave, implying the standard property that a higher signal $s$ indicates that a bad project is more likely. In (14),

$$
\sigma>0
$$

measures the "opacity" of the industry: a higher parameter $\sigma$ reflects less transparency, and, therefore, less precise information available to the activists. The industry's degree of opacity results from various components: the complexity of industrial projects, the transparency of regulation, and the expertise of NGO activists.

The following assumption rules out the least interesting cases identified above.

ASSUMPTION 2 (Non-extremist NGO):

(i) If the NGO were perfectly informed-as when $\sigma$ tends to zero-it would oppose the project when it is bad:

$$
\bar{s}<c_{H}
$$

(ii) If it were not informed at all-as when $\sigma$ tends to infinity-it would not oppose any project:

$$
p_{L} c_{L}+p_{H} c_{H}<\bar{s}
$$


Note that (16) implies

$$
\bar{s}>c_{L}
$$

i.e., a non-extremist perfectly informed NGO would not oppose a good project.

Assumption 2 allows our analysis to focus on the most interesting - and least obvious - case of an imperfectly informed NGO that would not remain inactive if it perfectly knew that the project was bad, but would not oppose it if it had no information at all.

In this context, the NGO opposition decision in the subgame perfect Bayesian equilibrium is resolved in details in online Appendix B. The results are summarized by the following proposition.

\section{PROPOSITION 3 (NGO Opposition):}

(i) If the regulator rejects bad projects, the NGO never mobilizes.

(ii) If the regulator approves all projects, regardless of whether they are good or bad, the NGO mobilizes (and induces the firm to abandon its project) with probability

$$
\Phi_{H}(\sigma) \equiv F\left(\frac{c_{H}-\hat{s}(\sigma)}{\sigma}\right)
$$

when the project is bad, and probability

$$
\Phi_{L}(\sigma) \equiv F\left(\frac{c_{L}-\hat{s}(\sigma)}{\sigma}\right)<\Phi_{H}(\sigma)
$$

when it is good.

(iii) As $\sigma$ increases and the industry becomes less transparent, the NGO mobilization probability $\Phi_{H}(\sigma)$ decreases; $\Phi_{L}(\sigma)$ is single peaked.

The proof is presented in online Appendix B. Probabilities $\Phi_{L}(\sigma)$ and $\Phi_{H}(\sigma)$ are depicted in Figure 4.

The inverted-U shape of the NGO opposition probability $\Phi_{L}(\sigma)$ means that, perhaps surprisingly, more transparency may induce more good projects to be abandoned. This property is consistent with the two following limit cases. If the NGO were perfectly informed that the project is good-as when $\sigma$ tends to zero-Assumption 2.1 implies that it would not oppose the project at all: $\lim _{\sigma \rightarrow+\infty} \Phi_{L}(\sigma)=0$. If the NGO had no information-as when $\sigma$ tends to infinity-it would not oppose it either, by Assumption 2.2: both $\Phi_{L}(\sigma)$ and $\Phi_{H}(\sigma)$ tend to zero in that case.

The next section examines how NGO opposition affects public regulation. 


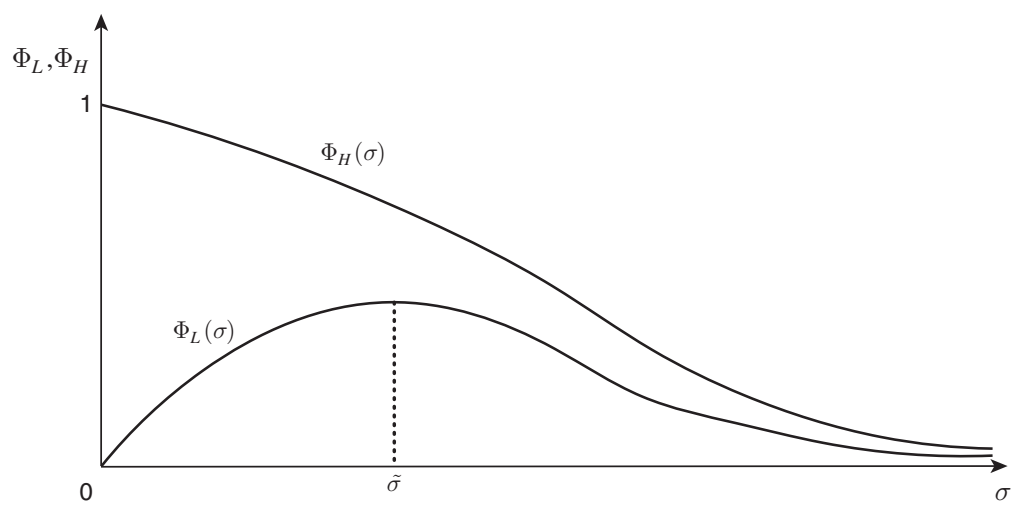

Figure 4. Probability of NGO Opposition to Good $\left(\Phi_{L}\right)$ and Bad $\left(\Phi_{H}\right)$ Projects

\section{Public Regulation with NGO Opposition}

Moving one step further back in the sequence of actions represented in Figure 3, we now consider the regulator's decision whether to reject the project when it is bad. If it does, this will be correctly anticipated by activists and NGO mobilization will never occur; in that case, the first-best outcome is realized. In contrast, if the regulator decides to approve the project when it is bad, the NGO will mobilize against the project with probability $\Phi_{H}(\sigma)$ given in (18).

We assume that the regulator does not internalize the cost of NGO mobilization: its objective is the same as (1). However, in the presence of activists, the implementation of the project becomes uncertain. Therefore, the regulator's objective must be written in expected terms: ${ }^{18}$

$$
\mathcal{V}=E[(1+\alpha(e)) \pi-\mathcal{C}]
$$

It follows that the minimum influence threshold $\bar{\alpha}$ required for the regulator to accept a bad project is the same as in Section I, regardless of the presence of activists. However, the presence of an NGO reduces the stakes of lobbying. Indeed, the industry anticipates that, if a bad project were accepted, it might ultimately be abandoned with probability $\Phi_{H}(\sigma)>0$ due to NGO opposition.

PROPOSITION 4 (Regulation and Lobbying with NGO Opposition): In the presence of an NGO, lobbying takes place if and only if

$$
\sigma \geq \sigma^{R N}\left(\frac{i}{q}\right) \equiv \Phi_{H}^{-1}\left(1-\left(\frac{i}{q}\right) \frac{c_{H}-v}{p_{H} v^{2}}\right)
$$

\footnotetext{
${ }^{18}$ Online Appendix D explains how the analysis would be modified if the regulator internalized the social cost of NGO mobilizations, or if he incurred a private reputational cost from their occurrence.
} 


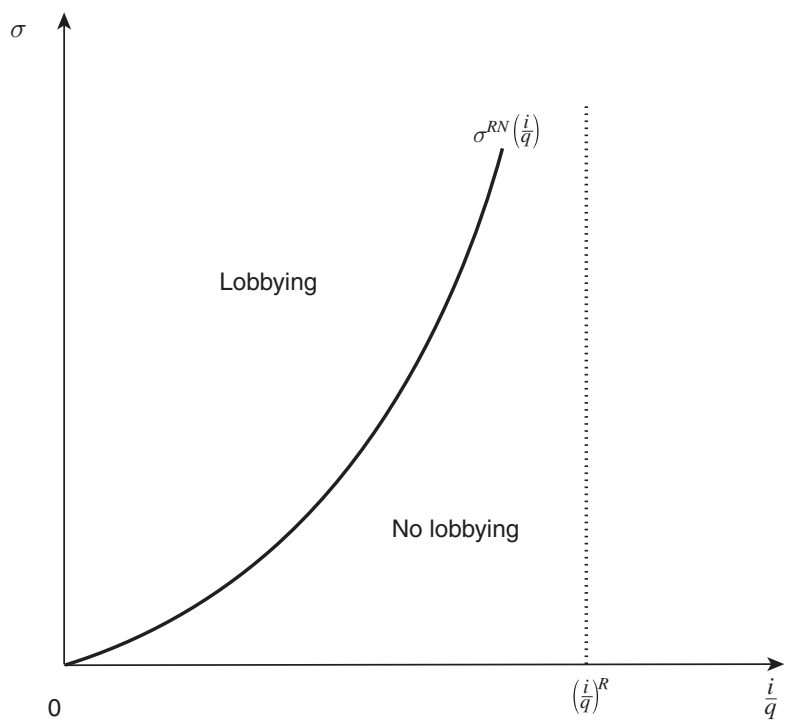

Figure 5. Occurrence of Industry Lobbying in the Presence of An NGO

The proof of Proposition 4 is presented in online Appendix B. Its result is illustrated in Figure 5 in the $(i / q, \sigma)$ plane. It shows that the threshold function $\sigma^{R N}(i / q)$ exhibits an asymptote at level $(i / q)^{R}$, the lobbying threshold in the absence of an NGO. Indeed, when $\sigma$ is infinite-i.e., without information-there is no NGO opposition, so that lobbying takes place under the same condition whether there is an NGO or not.

In the absence of lobbying, there is no NGO opposition, so the social surplus generated by the industry is the first-best level, as in (5):

$$
\mathcal{W}_{L}^{R N}=\mathcal{W}_{L}^{R}=p_{L}\left(v-c_{L}\right) q>0
$$

When the industry lobbies effectively, however, expected welfare becomes

$$
\begin{aligned}
\mathcal{W}_{L H}^{R N}= & p_{L}\left[\left(1-\Phi_{L}(\sigma)\right)\left(v-c_{L}\right)-\Phi_{L}(\sigma) \gamma \eta(\omega) v\right] q \\
& +p_{H}\left[\left(1-\Phi_{H}(\sigma)\right)\left(v-c_{H}\right)-\Phi_{H}(\sigma) \gamma \eta(\omega) v\right] q-i \bar{\alpha} .
\end{aligned}
$$

As in Section I, we rule out the uninteresting situation in which it would be socially optimal to simply shut down the industry by assuming ${ }^{19}$

$$
\mathcal{W}_{L H}^{R N} \geq 0
$$

\footnotetext{
${ }^{19}$ In some cases, however, industry projects were banned only because they were meeting NGO opposition. This was especially evident when France banned GMO cultivation in 2014: the decision was justified by the opposition of the public, as demonstrated by opinion polls and by activists' destruction of experimental GMO fields (Reuters, May 5, 2014, available at http://www.reuters.com/article/2014/05/05/france-gmo-idUSL6N0NR2MZ20140505).
} 
The next section characterizes the occurrence of lobbying with and without an NGO.

\section{Occurrence of Industry Lobbying, Endogenous NGO Entry, and Welfare Analysis}

In this section, we first characterize the circumstances under which industry lobbying takes place with and without an NGO. Then, we endogenize the NGO entry decision and examine the welfare impact of this decision.

According to Propositions 1 and 4, the occurrence of lobbying depends on both the relative cost of influence and the degree of transparency in the industry. The following corollary is immediately obtained-see online Appendix B.

COROLLARY 1 (Occurrence of Lobbying):

(i) For high relative costs of influence $i / q>(i / q)^{R}$, lobbying never takes place, regardless of whether there is an NGO or not.

(ii) For low relative costs of influence $i / q \leq(i / q)^{R}$ and

(a) Low degrees of transparency $\sigma \geq \sigma^{R N}(i / q)$, the industry always lobbies;

(b) High degrees of transparency $\sigma<\sigma^{R N}(i / q)$, the industry lobbies in the absence of an NGO, and does not otherwise.

The corollary shows that the presence of an NGO limits the occurrence of industry lobbying, as is illustrated in the $(i / q, \sigma)$ plane in Figure 6.

\section{A. Endogenous NGO Entry}

Sections I and III examined the performance of an industry with and without an NGO. We now endogenize the NGO's entry decision. ${ }^{20}$ When the NGO enters, activists dedicate resources to the monitoring of the industry's project and, based on the information they collect, decide whether to oppose this project in the way described above.

The NGO enters when it believes that this will reduce its valuation $\chi$ of the expected external cost inclusive of the cost of mobilizing against the project. Therefore, we compare $\chi$ in the presence and absence of the NGO in the industry, in the three situations identified in Corollary 1.

Consider first the situation in which industry lobbying never takes place and the regulator only approves the project when it is good. In this case, there is no NGO opposition, even in the presence of the NGO, as per Proposition 4. With or without the NGO, the activists' cost valuation is

$$
\chi_{L}^{R}=\chi_{L}^{N R}=p_{L} c_{L} q
$$

\footnotetext{
${ }^{20}$ The coordination of individual activists and the NGO's formation are beyond the scope of this paper.
} 


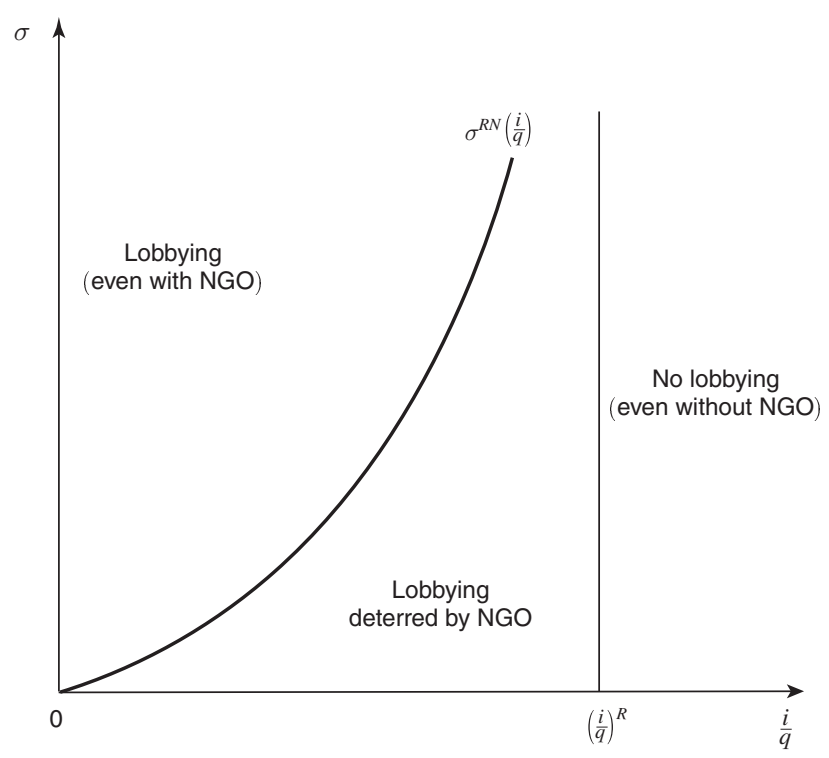

FIGURE 6. OCCURRENCE OF INDUSTRY LOBBYING WITH AND WITHOUT AN NGO

NGO entry, therefore, would not reduce the cost valuation $\chi$ of activists.

Second, consider the situation in which industry lobbying only induces the approval of a bad project in the absence of the NGO. In that case, Proposition 1 implies that the activists' cost valuation is

$$
\chi_{L H}^{R}=\left(p_{L} c_{L}+p_{H} c_{H}\right) q
$$

which is greater than in (24). Therefore, the NGO's entry causes a change $\chi_{L}^{R N}-\chi_{L H}^{R}<0$. In that case, the activists always enter.

Third, consider the situation in which the industry lobbies the regulator regardless of the NGO's presence. In the absence of the NGO, the activists' cost valuation is given by $(25)$, which is to be compared with their valuation in the presence of NGO opposition. By Propositions 2 and 3, the latter is ${ }^{21}$

$$
\begin{aligned}
\chi_{L H}^{R N}= & p_{L}\left[\left(1-\Phi_{L}(\sigma)\right) c_{L}+\Phi_{L}(\sigma) \gamma \eta(\omega) v\right] q \\
& +p_{H}\left[\left(1-\Phi_{H}(\sigma)\right) c_{H}+\Phi_{H}(\sigma) \gamma \eta(\omega) v\right] q .
\end{aligned}
$$

Analysis of the difference $\chi_{L H}^{R N}-\chi_{L H}^{R}$ yields that the NGO always enters in that case-see the proof in online Appendix B. The above results are summarized by the following proposition.

\footnotetext{
${ }^{21}$ At this stage, the expected cost valuation of activists is an expectation not only over the realization of the project (good or bad), but also over the realization of the signal $s$, which depends on the project's type.
} 
PROPOSITION 5 (NGO Entry and Industry Lobbying): The activist NGO enters if and only if $0<i / q \leq(i / q)^{R}$-i.e., whenever the industry lobbies in its absence. ${ }^{22}$

\section{B. NGO-Induced Welfare Improvement}

The question arises whether the entry decision of the NGO activists analyzed in the previous subsection contributes to improve welfare. Indeed, the NGO is only concerned with the expected cost $\chi=E^{N}[\mathcal{C}+\gamma m]$ which, unlike social welfare

$$
\mathcal{W}=E[\pi-\mathcal{C}-\gamma m-i \alpha]=E[\pi-\chi-i \alpha],
$$

does not take into account the industry's profit and cost of lobbying.

To address the welfare impact of the NGO's entry, it is useful to first establish the circumstances under which this entry deters industry lobbying. We do so in the following corollary—see online Appendix B.

COROLLARY 2 (NGO's Deterrence of Lobbying): NGO entry deters industry lobbying if and only if $\sigma<\sigma^{R N}(i / q)$-i.e., whenever the information at its disposal is sufficiently precise.

We now examine the impact on welfare of the NGO's entry decision. When industry lobbying never takes place and the regulator only approves the project when it is good, the first-best outcome is realized despite the fact that the NGO does not enter. Social welfare in that case is given by (21), which would not be improved by the NGO's entry.

When industry lobbying is deterred by the NGO's entry, the first-best welfare level (21) is restored: indeed, the mere presence of the NGO is sufficient in that case, and NGO mobilization is not needed: the NGO's entry is always desirable.

Finally, when industry lobbying takes place regardless of whether there is an NGO or not, social welfare $\mathcal{W}_{L H}^{R}$ without an NGO, as given in (6), is to be compared with its counterpart $\mathcal{W}_{L H}^{R N}$ in the presence of an NGO, as given in (22). Analysis of the difference yields the following proposition.

PROPOSITION 6 (Welfare Impact of NGO Activism):

(i) NGO entry always improves social welfare when it deters industry lobbying.

(ii) When it does not deter lobbying, NGO entry improves welfare if

(a) Mobilizations are not too costly: $\gamma<\bar{\gamma} \equiv \frac{c_{H}-v}{\eta(\omega) v}$;

(b) And there is enough transparency in the industry: $\sigma<\sigma^{*}(\gamma)$, where $\sigma^{*}(\gamma)$ is defined in online Appendix B.

${ }^{22}$ It should be clear from Corollary 1, however, that NGO entry does not necessarily deter lobbying. 
Panel A. High mobilization cost: $\gamma \geq \bar{\gamma}$

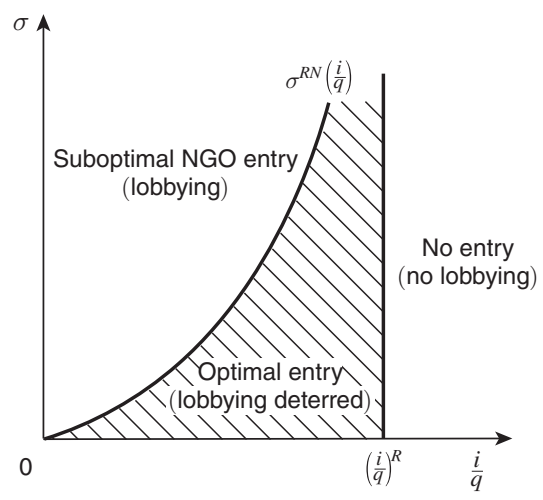

Panel B. Low mobilization cost: $\gamma<\bar{\gamma}$

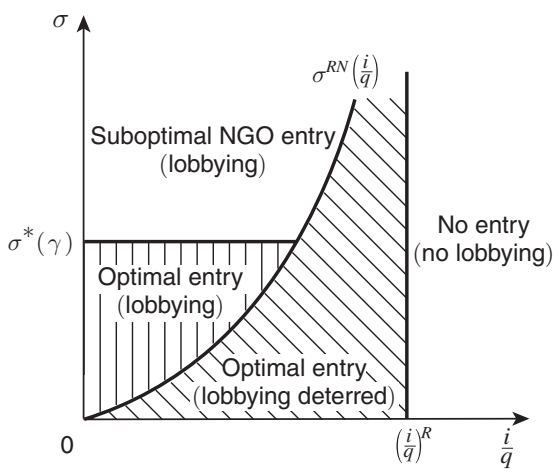

Figure 7. Optimality of NGO Entry

The proof of Proposition 6 is presented in online Appendix B. Its result is represented in Figure 7. In panel A, the cost of NGO mobilization is high $(\gamma \geq \bar{\gamma})$ : NGO entry only improves welfare when it deters lobbying (hatched area). In panel $\mathrm{B}$, the cost of NGO mobilization is low $(\gamma<\bar{\gamma})$. In that case, there exists a threshold degree of opacity $\sigma^{*}(\gamma)>0$-decreasing in the mobilization efficiency parameter $\gamma$-below which the NGO's entry is optimal, not because it deters industry lobbying, but because NGO activists can efficiently oppose harmful industrial projects (vertically hatched area).

In environments favorable to the industry's influence, the involvement of NGO activists may become optimal for society for two reasons. First, NGOs tend to deter industry lobbying. Thus, in the presence of an NGO, regulation is less vulnerable to the industry's influence. Second, even when the industry's influence is unavoidable, activists directly oppose industrial projects.

Yet NGO opposition is a costly way to fight an industry's influence on its regulation, not only because NGO-industry conflicts are socially costly, but also because NGOs sometimes pick the wrong target. Indeed, our analysis stresses the crucial role of transparency. As Figure 7 illustrates, a perfectly informed NGO — as when $\sigma$ tends to zero and the diagram reduces to its horizontal axis-would always improve welfare, despite the fact that its mobilization is socially costly: its presence would systematically deter the influence of the industry on regulation, making NGO opposition unnecessary. Some opacity $(\sigma>0)$ is needed to explain the fact that NGO entry does not necessarily deter lobbying and that NGO mobilizations effectively take place.

When an NGO becomes more efficient and when its information improves, it chooses better targets and reaches them in a less costly way. In that context, Proposition 6 demonstrates that NGO opposition has the potential to improve the existing regulatory system.

\section{Implications for the Rise of NGO Activism}

Our theory can be used to explain the increasing involvement of NGOs in several industries over the past few decades. In a nutshell, our view is that the size and 
value of industrial projects (and thus the stakes of lobbying) have grown dramatically, while the cost of influence has not increased in most countries (and probably decreased in some). Public regulation has thus become more vulnerable. At the same time, conditions have favored NGOs' efficiency, such as the rise of communication technologies and the resulting dissemination of information. As a result, NGOs have increasingly sought to oppose the hazardous projects of industries that are difficult to regulate.

\section{A. The Rising Scale of Projects and the Resulting Influence of the Industry on Public Regulation}

In Western countries, firms have typically grown in size rapidly in the last three decades. More and more, multinational conglomerates operate in oil and energy production, banking, retailing, food production, new technologies, etc. This is mainly because technology accelerated economies of scale and increased entry costs (Bollard, Klenow, and Li 2014; Mueller, Ouimet, and Simintzi 2017), thereby "allowing the biggest firms to get bigger unhindered by competition" (The Economist 2015). ${ }^{23}$ In developing countries, businesses have grown in size both because of economic development and because super big companies emerged from state capitalism.

At the same time, industrial projects have grown bigger, whether in size or valuation, and their potential external damages have scaled up accordingly. For example, outcomes such as the Deepwater Horizon explosion, the Fukushima disaster, and the global financial crisis became catastrophes because the units involved were of record size. ${ }^{24}$

Glaeser and Shleifer (2003) shows that public regulation was the optimal way for society to regulate business in Western countries between the start of the Progressive Era, and, roughly, the Second World War. However, the progressive program could not keep its promises in the face of today's enormous stakes. The contemporary era instead sees Western governments under the thumb of super-big multinationals and not in a position to impose adequate standards on them. In some sectors, businesses are so powerful that they manage to effectively distort regulation incentives with enormous political contributions, ubiquitous lobbying efforts, occasional corruption, or more complex and subtle forms of influence. This has been the case of energy regulation in many instances, but also of the regulation of the banking sector and the food and drugs industries worldwide.

\section{B. The Rising Efficiency of NGO Activism}

When governments and regulators have failed to impose adequate standards for powerful businesses, NGOs have gotten increasingly effective at mobilizing to

\footnotetext{
${ }^{23}$ The Economist. 2015. "The Bigger, the Less Fair," March 12. https://www.economist.com/ finance-and-economics/2015/03/12/the-bigger-the-less-fair.

${ }^{24}$ It is remarkable that the Deepwater Horizon rig was drilling the deepest oil well in history, and that the Fukushima Daiichi nuclear power plant was one of the 15 largest power stations in the world. Furthermore, when businesses are interconnected, as in the banking sector, firm size is more critical than ever, because interconnection magnifies the social damages of misconduct.
} 
address such failures. ${ }^{25}$ Opposition to super-big corporations and projects seems inherent to the rise of NGOs, both because big businesses are typically suspected of causing the greatest harm, and because they are more vulnerable to reputational risks.

Another remarkable change that has characterized the last few decades is the emergence of the internet and associated communication technologies (ICT, hereafter). As Nye (2004) points out, the ICT revolution has dramatically accelerated the rise of NGOs. According to our theory, there are two important aspects: information quality and mobilization efficiency. First, the ICT revolution has facilitated NGOs' ability to identify issues to oppose. Indeed, information is increasingly being disseminated at the global level about everything and, a fortiori, about industrial projects and their regulatory treatment. To sum up, in the words of The Economist, "The Internet [has] greatly improved transparency. Corporate secrets are becoming ever harder to keep." 26,27 Second, the ICT revolution greatly improved the ways in which the public can be mobilized through social media, as well as NGOs' ability to coordinate their efforts through networks. ${ }^{28}$

\section{NGO Activism as a Response to These Recent Changes}

According to our theory, therefore, the economy has moved, over the last few decades, in the southwest direction in the diagrams in Figure 7. On the one hand, in the face of greater industrial stakes, public regulation has become more susceptible to pressure from industry to approve hazardous projects. In our model, this means a fall in the relative cost of influence $i / q$. On the other hand, NGO activism has benefitted from improved communication technologies and gotten increasingly better at targeting harmful projects. This means a fall in the parameter $\sigma$ measuring opacity. Our theory, therefore, suggests that the involvement of NGO activists was a response to the recent changes described above.

The remaining question is whether this response was legitimate from the perspective of society as a whole. For example, Nye (2004) considers that the rise of NGO opposition has contributed to social progress. Improved communication technologies have not only generated more transparency, but also favored activists' efficiency in opposing targeted projects. This means a fall in the cost of mobilization $\gamma$ : the economy would have moved from the diagram on the left in Figure 7 to the diagram on the right, and in the southwest direction in the latter. In that context, NGO opposition was more likely to be socially optimal as $\sigma$ decreased, for two reasons.

\footnotetext{
${ }^{25}$ For example, our analysis already mentioned the effective opposition to Nike's outsourced production management, Citigroup's project funding, HSBC's risk management, TransCanada's and Shell's energy-related projects, Starbucks's tax-avoidance scheme, and Dunkin's Donuts's use of chemicals.

${ }^{26}$ The Economist. 2004. "Easy to Lose," January 22. https://www.economist.com/special-report/2004/01/24/ easy-to-lose.

${ }^{27}$ Baron $(2003,34-35)$ illustrates the changes in NGO strategies that resulted from the ICT revolution. For example, he describes environmental activists' rapid circulation of information released by the Environmental Protection Agency. Similarly, an essay by the head of a NASA research institute was circulated in 2011, which informed NGOs about the Keystone XL pipeline's being on the track for approval.

${ }^{28}$ This is well illustrated by recent mobilizations, such as the opposition to TransCanada's exploratory drilling in Québec in 2014.
} 
On the one hand, NGOs became better at detecting the most hazardous projects. On the other hand, with more transparency, NGOs became more effective at deterring industry lobbying. For example, over the period 2002-2014 in the United States, NGOs' criticisms have been negatively associated with companies' subsequent lobbying expenditures (see the details in online Appendix A). Thus, our theory tells that the rise of NGO activism is socially optimal if the joint decrease in $\sigma$ and $\gamma$ has been sufficiently marked.

\section{Other Possible Policy Responses}

Ahead of more vulnerable public regulation, our theory suggests other responses besides NGO activism that could contribute to social progress. The first and most obvious would be to strengthen regulation's ability to resist industry influence by increasing the cost of influence $i$. This is, for example, the message of the Tobin Project initiative and of Carpenter and Moss's (2014) book, which calls for more attention to how the influence of special interests can be limited. Especially in reaction to the global financial crisis, the call for the prevention of capture found a particular echo in the US policy arena in 2009-2010, with the creation of new agencies under the 2010 Dodd-Frank Act. The question still arises, however, how agencies should be designed to increase their independence (see, for example, the measures suggested by Sheng 2012, 157). ${ }^{29}$

The second response would be to increase transparency in regulatory affairs, which amounts to decreasing $\sigma$. NGOs often call for more transparency. ${ }^{30}$ In turn, more transparency in regulation is likely to contribute to limiting special interests' influence over regulators and policymakers by improving the latter's accountability.

Last, the cost of NGO opposition $\gamma$ could be lowered by involving NGOs more directly in the regulatory process. For example, in his measures to prevent regulatory capture, Sheng (2012) suggests the empowerment of stakeholders as a countervailing power. This raises other questions, such as the independence of NGOs, that go beyond the scope of our analysis.

\section{E. The Legal Status of NGO Activism}

Our theory rests on the assumption that the rise of NGOs occurred when activists perceived that their involvement would be an effective way to contribute to the

\footnotetext{
${ }^{29}$ Indeed, as shown by Gibson Brandon and Padovani (2011), strengthened regulation-as per the Dodd-Frank Act-has led to an increase in lobbying efforts by the US banking industry. Their finding is consistent with our theory: starting from an environment highly favorable to the industry's influence, an increase in $i$ that is not sufficient to deter lobbying only increases influence expenditures $i \bar{\alpha}$.

${ }^{30}$ US environmentalists, for example, backed legislation by which the EPA must make information about chemical emissions public. Similarly, in states in which fracking is approved by regulation, anti-fracking activists have often demanded, with some success, that the fluids injected underground be disclosed. The idea that transparency must be improved has also found a particular echo in the debate on financial regulation; improved transparency was one objective of the Dodd-Frank Act. Moreover, the academic literature on financial regulation has suggested that the disclosure of financial data collected by regulators to third parties may improve regulators' incentives (Landier and Thesmar 2011).
} 
resolution of externalities. This is only possible when and where NGO activism is allowed by the legal environment.

Notably, the legal status of activism is ambiguous in most countries. Activism is generally tolerated by law in developed countries; sometimes, it is even guaranteed some financial independence. ${ }^{31}$ Yet the right to protest only applies as long as protests do not break the law. When activist campaigns involve extreme behavior, activists often run the risk of legal repercussions. Even peaceful actions, such as calls for boycotts, may violate refusal-to-deal, anti-discrimination, and anti-defamation laws. ${ }^{32}$

The legal protection of NGO activism is a more urgent issue for developing countries. In transitional economies and emerging markets, NGOs are often banned, especially in autocratic governments, on the ground that their opposition to the industry destroys business - see, e.g., The Economist. ${ }^{33}$ Our analysis calls for more protection of NGOs, and especially in these contexts, so that NGOs can effectively play their role of countervailing and disciplinary power.

\section{Conclusion}

To sum up, this theory holds that public regulation becomes vulnerable to the industrial stakes both when the cost of influence declines and economic activity grows. In either case, NGO activists may enter. When NGOs are sufficiently efficient and transparency allows them to be sufficiently well informed, activism against industrial projects is warranted. Our theory highlights the fundamental importance of transparency. Activists may only countervail the industry's influence if they have access to information of a sufficient quality to distinguish a bad project from a good one.

Two aspects are absent from the framework presented above, but are discussed in online Appendix D. First, our analysis carries over unchanged to the apparently more complex case in which the firm is able to make lobbying efforts that are specific to the project's type. Second, the analysis accommodates situations in which the regulator is directly affected by NGO opposition. For example, McDonnell and Werner (2016) shows that policymakers are less willing to associate with firms targeted by activists. Our results remain qualitatively the same under the assumption that the regulator is directly affected by NGO opposition to a project that it approved. The extension, nevertheless, highlights that the regulator's sensitiveness to NGO mobilization reinforces the result that the NGO presence can deter industry lobbying.

This paper is in line with Glaeser and Shleifer's (2003) analysis of the rise of public regulation at the dawn of the twentieth century-see also Shleifer (2012). Glaeser and Shleifer explain the predominance of public regulation over private

\footnotetext{
${ }^{31}$ For instance, the Dutch government financially supports human rights activist groups.

${ }^{32}$ It is on these grounds, for example, that several calls for boycotts by the French consumer association UFC have been declared unlawful. For its call to boycott Shell in response to the wreck of the Amoco-Cadiz oil tanker, the UFC was fined a prohibitive amount, which corresponded to Shell's estimated lost sales.

${ }^{33}$ The Economist. 2015. "Who's Afraid of the Activists?" May 9. https://www.economist.com/asia/2015/05/09/ whos-afraid-of-the-activists.
} 
litigation by the fact that the former proved less vulnerable than the latter in the face of growing industrial stakes. We suggest that during the second half of the twentieth century, the size and value of industrial projects (and thus the stakes of lobbying) have grown dramatically. Public regulatory decisions have thus become more vulnerable to the influence of large companies. At the same time, conditions have favored NGOs' efficiency, such as the rise of communication technologies and the resulting dissemination of information. As a result, NGOs have increasingly sought to oppose the hazardous projects of industries that are difficult to regulate. In other words, NGO activism has been one way society can rebalance public and private interests - as a complement to public regulation.

The objective of activist NGOs need not be aligned with the preferences of society as a whole. Provided they are not extremist, their opposition is reminiscent of Coasian bargaining. According to Coase (1960), bargaining's appeal is its potential to resolve externalities when transaction costs are low. In this respect, we point to two costs of NGO activism. First, NGO mobilizations and campaigns consume financial and human resources that could be used elsewhere. Second, activists may mistakenly oppose socially beneficial projects partly due to their imperfect information. We argue that the internet and social media have contributed to a decrease in both types of costs.

In this paper, we have focused on the influential aspect of industry lobbying. Indeed, as justified in Section I, lobbying is more a matter of influence than information. Moreover, our analysis deals with regulators, who are appointed for their expertise. In that context, the most remarkable asymmetry of information is not between the industry and its regulators, but between, on the one hand, the industry and its regulators, and, on the other hand, NGO activists who have no direct access to industrial projects.

Informational lobbying is, however, probably more relevant for other branches of governments than it is for public regulation. Legislators, for example, rely on a substantial amount of information that is provided not only by the industry but also by NGOs. In such a context, the analysis of the role of NGOs is more difficult because informational lobbying impacts the degree of transparency. On the one hand, it is often argued that competition among information providers improves the incentive to disclose truthful information (Dewatripont and Tirole 1999). On the other hand, however, this competition may generate more opacity for two reasons. First, information externalities tend to discourage the collection/production of information by interest groups (Bennedsen and Feldmann 2006). Second, interest groups may seek to undermine the credibility of other groups, weakening the transmission of information to decision makers (Chiroleu-Assouline and Lyon 2016). Clearly, the role of NGOs in contexts of informational lobbying is an exciting and promising field for future research.

\section{REFERENCES}

Acemoglu, Daron, and Miles B. Gietzmann. 1997. "Auditor Independence, Incomplete Contracts and the Role of Legal Liability.” European Accounting Review 6 (3): 355-75.

Aghion, Philippe, Yann Algan, Pierre Cahuc, and Andrei Shleifer. 2010. "Regulation and Distrust." Quarterly Journal of Economics 125 (3): 1015-49. 
Baron, David P. 2001. "Private Politics, Corporate Social Responsibility, and Integrated Strategy." Journal of Economics and Management Strategy 10 (1): 7-45.

Baron, David P. 2003. "Private Politics." Journal of Economics and Management Strategy 12 (1): 31-66.

Baron, David P. 2010. "Morally Motivated Self-Regulation." American Economic Review 100 (4): 1299-1329.

Baron, David P. 2012. “The Industrial Organization of Private Politics.” Quarterly Journal of Political Science 7 (2): 135-74.

Baron, David P., and Daniel Diermeier. 2007. "Strategic Activism and Nonmarket Strategy." Journal of Economics and Management Strategy 16 (3): 599-634.

Baron, David P., and Erin Yurday. 2004. "Anatomy of a Corporate Campaign: Rainforest Action Network and Citigroup." Stanford University Case Study P42A.

Bénabou, Roland, and Jean Tirole. 2006. "Incentives and Pro-social Behavior." American Economic Review 96 (5): 1652-78.

Bennedsen, Morten, and Sven E. Feldmann. 2006. "Informational Lobbying and Political Contributions." Journal of Public Economics 90 (4-5): 631-56.

Bertrand, Marianne, Matilde Bombardini, Raymond Fisman, and Francesco Trebbi. 2018. "Tax-Exempt Lobbying: Corporate Philanthropy as a Tool for Political Influence." NBER Working Paper 24451.

Bertrand, Marianne, Matilde Bombardini, and Francesco Trebbi. 2014. "Is It Whom You Know or What You Know? An Empirical Assessment of the Lobbying Process." American Economic Review 104 (12): 3885-3920.

Besley, Timothy, and Maitreesh Ghatak. 2005. "Competition and Incentives with Motivated Agents." American Economic Review 95 (3): 616-36.

Bollard, Albert, Peter J. Klenow, and Huiyu Li. 2014. "Entry Costs Rise with Development." http:// econ.sciences-po.fr/sites/default/files/file/pete-klenow.pdf.

Buchanan, James M., Robert D. Tollison, and Gordon Tullock, eds. 1980. Toward a Theory of the Rent-Seeking Society. College Station: Texas A\&M Press.

Carpenter, Daniel, and David A. Moss, eds. 2014. Preventing Regulatory Capture: Special Interest Influence and How to Limit It. Cambridge, UK: Cambridge University Press.

Carpenter, Hayley. 2015. "Deepwater Horizon: Agency Reorganization and Appropriations in Offshore Oil Regulation.” Ecology Law Quarterly 42 (2): 181-208.

Center for Responsive Politics. 2014. "Lobbying Database." https://www.opensecrets.org/lobby (accessed December 8, 2015).

Chiroleu-Assouline, Mireille, and Thomas P. Lyon. 2016. "Merchants of Doubt: Corporate Political Influence When Expert Credibility Is Uncertain.” CESifo Working Paper 6165.

Coase, Ronald H. 1960. "The Problem of Social Cost." Journal of Law and Economics 3: 1-44.

Couttenier, Mathieu, Pierre Fleckinger, Matthieu Glachant, and Sophie Hatte. 2016. "Communication Strategies of NGOs: Theory and Evidence." www.cerna.mines-paristech.fr/Donnees/data15/1511Pres_Montpellier.pdf.

Couttenier, Mathieu, and Sophie Hatte. 2016. "Mass Media Effects on Non-governmental Organizations." Journal of Development Economics 123: 57-72.

Covalence Ethical Quote. 2014. "NGO Database." https://www.covalence.ch/index.php/services/ universities/ (accessed December 8, 2015).

Culling, Joshua. 2017. “Revving Up Your Reputation.” World Trademark Review 64 (December 2016/ January 2017): 56-59.

Daubanes, Julien, and Jean-Charles Rochet. 2019. "The Rise of NGO Activism: Dataset." American Economic Journal: Economic Policy. https://doi.org/10.1257/pol.20180027.

Dewatripont, Mathias, and Jean Tirole. 1999. "Advocates." Journal of Political Economy 107 (1): 1-39.

Dixit, Avinash K. 2004. Lawlessness and Economics: Alternative Modes of Governance. Princeton: Princeton University Press.

Djankov, Simeon, Rafael La Porta, Florencio Lopez-de-Silanes, and Andrei Shleifer. 2002. "The Regulation of Entry." Quarterly Journal of Economics 117 (1): 1-37.

Doh, Jonathan P., and Terrence R. Guay. 2006. "Corporate Social Responsibility, Public Policy, and NGO Activism in Europe and the United States: An Institutional-Stakeholder Perspective." Journal of Management Studies 43 (1): 47-73.

Duchin, Ran, and Denis Sosyura. 2012. "The Politics of Government Investment." Journal of Financial Economics 106 (1): 24-48. 
Egorov, Georgy, and Bård Harstad. 2017. "Private Politics and Public Regulation." Review of Economic Studies 84 (4): 1652-82.

Friedman, Monroe. 1999. Consumer Boycotts: Effecting Change through the Marketplace and the Media. London: Routledge.

Galbraith, John K. 1952. American Capitalism: The Concept of Countervailing Power. Boston: Houghton Mifflin.

Gans, Joshua S., and Sarah Kaplan, eds. 2017. Survive and Thrive: Winning against Strategic Threats to Your Business. Indianapolis: Dog Ear Publishing.

Gibson Brandon, Rajna, and Miret Padovani. 2011. “The Determinants of Banks' Lobbying Activities." Swiss Finance Institute Research Paper 11-56.

Glaeser, Edward L., and Andrei Shleifer. 2003. "The Rise of the Regulatory State." Journal of Economic Literature 41 (2): 401-25.

Godwin, Ken, Scott H. Ainsworth, and Erik Godwin. 2013. Lobbying and Policymaking: The Public Pursuit of Private Interests. Washington, DC: Congressional Quarterly Press.

Goldberg, Pinelopi K., and Giovanni Maggi. 1999. "Protection for Sale: An Empirical Investigation." American Economic Review 89 (5): 1135-55.

Grossman, Gene M., and Elhanan Helpman. 2001. Special Interest Politics. Cambridge: MIT Press.

Harrison, Ann, and Jason Scorse. 2010. "Multinationals and Anti-sweatshop Activism." American Economic Review 100 (1): 247-73.

Heyes, Anthony G., and Steve Martin. 2016. "Social Labeling by Competing NGOs: A Model with Multiple Issues and Entry." Management Science 63 (6): 1800-1813.

Hiriart, Yolande, and David Martimort. 2012. "How Much Discretion for Risk Regulators?" RAND Journal of Economics 43 (2): 283-314.

Hiriart, Yolande, David Martimort, and Jerome Pouyet. 2010. "The Public Management of Risk: Separating Ex Ante and Ex Post Monitors." Journal of Public Economics 94 (11-12): 1008-19.

Hofstadter, Richard. 1955. The Age of Reform. New York: Random House.

Igan, Deniz, Prachi Mishra, and Thierry Tressel. 2011. "A Fistful of Dollars: Lobbying and the Financial Crisis.” NBER Macroeconomics Annual 26 (1): 195-230.

Innes, Robert, and Abdoul G. Sam. 2008. "Voluntary Pollution Reductions and the Enforcement of Environmental Law: An Empirical Study of the 33/50 Program." Journal of Law and Economics 51 (2): 271-96.

King, Brayden G., and Sarah A. Soule. 2007. "Social Movements as Extra-Institutional Entrepreneurs: The Effect of Protests on Stock Price Returns." Administrative Science Quarterly 52 (3): 413-42.

Kofman, Fred, and Jacques Lawarrée. 1993. "Collusion in Hierarchical Agency." Econometrica 61 (3): 629-56.

Krautheim, Sebastian, and Thierry Verdier. 2016. "Offshoring with Endogenous NGO Activism." Journal of International Economics 101: 22-41.

Laffont, Jean-Jacques. 1994. "The New Economics of Regulation Ten Years After." Econometrica 62 (3): 507-37.

Laffont, Jean-Jacques. 2005. Regulation and Development. Cambridge: Cambridge University Press.

Laffont, Jean-Jacques, and Jean Tirole. 1991. "The Politics of Government Decision-Making: A Theory of Regulatory Capture." Quarterly Journal of Economics 106 (4): 1089-1127.

Laffont, Jean-Jacques, and Jean Tirole. 1993. A Theory of Incentives in Procurement and Regulation. Cambridge: MIT Press.

Landier, Augustin, and David Thesmar. 2011. "Regulating Systemic Risk Through Transparency: Tradeoffs in Making Data Public." NBER Working Paper 17664.

Lyon, Thomas P., and John W. Maxwell. 2003. "Self-Regulation, Taxation and Public Voluntary Environmental Agreements." Journal of Public Economics 87 (7-8): 1453-86.

Lyon, Thomas P., and Stephen W. Salant. 2015. "Linking Public and Private Politics: Activist Strategy for Industry Transformation.” https://pdfs.semanticscholar.org/64e7/3b5ddf87170c645bcaf63c913 d513c61c2cc.pdf.

McDonnell, Mary-Hunter, and Timothy Werner. 2016. "Blacklisted Businesses: Social Activists' Challenges and the Disruption of Corporate Political Activity." Administrative Science Quarterly 61 (4): 584-620.

McGrath, Conor. 2006. "The Ideal Lobbyist: Personal Characteristics of Effective Lobbyists." Journal of Communication Management 10 (1): 67-79.

Maxwell, John W., Thomas P. Lyon, and Steven C. Hackett. 2000. "Self-Regulation and Social Welfare: The Political Economy of Corporate Environmentalism." Journal of Law and Economics 43 (2): 583-617. 
Mian, Atif, Amir Sufi, and Francesco Trebbi. 2010. "The Political Economy of the US Mortgage Default Crisis." American Economic Review 100 (5): 1967-98.

Mueller, Holger M., Paige P. Ouimet, and Elena Simintzi. 2017. "Wage Inequality and Firm Growth." American Economic Review 107 (5): 379-83.

Nye, Joseph S. 2004. “The Rising Power of NGO's." Project Syndicate, June 24. http://www.projectsyndicate.org/commentary/the-rising-power-of-ngo-s.

Sheng, Andrew. 2012. "Regulatory Capture: A Former Regulator's Perspective." In Making Good Financial Regulation: Towards a Policy Response to Regulatory Capture, edited by Stefano Pagliari, 149-58. London: Grosvenor House Publishing.

Shleifer, Andrei. 2012. The Failure of Judges and the Rise of Regulators. Cambridge: MIT Press.

Stigler, George J. 1971. "The Economic Theory of Regulation." Bell Journal of Economics and Management Science 2 (1): 3-21.

Stiglitz, Joseph E. 1994. Whither Socialism? Cambridge: MIT Press.

Tabellini, Guido. 2008. "The Scope of Cooperation: Values and Incentives." Quarterly Journal of Economics 123 (3): 905-50.

Tirole, Jean. 1986. "Hierarchies and Bureaucracies: On the Role of Collusion in Organizations." Journal of Law, Economics, and Organization 2 (2): 181-214.

Wang, Qiang, and Xi Chen. 2012. "Regulatory Failure for Nuclear Safety-The Bad Example of Japan-Implication for the Rest of the World." Renewable and Sustainable Energy Reviews $16(5): 2610-17$.

Yu, Zhihao. 2005. "Environmental Protection: A Theory of Direct and Indirect Competition for Political Influence." Review of Economic Studies 72 (1): 269-86. 
This article has been cited by:

1. Mireille Chiroleu-Assouline, Thomas P. Lyon. 2020. Merchants of doubt: Corporate political action when NGO credibility is uncertain. Journal of Economics \& Management Strategy 88. . [Crossref] 